\title{
Estimating chlorophyll profiles from electronic tags deployed on pelagic animals
}

\author{
Steven L. H. Teo ${ }^{1,4, *}$, Raphael M. Kudela ${ }^{2}$, Amber Rais ${ }^{1}$, Chris Perle $^{1}$, Daniel P. Costa ${ }^{3}$, \\ Barbara A. Block ${ }^{1}$ \\ ${ }^{1}$ Tuna Research and Conservation Center, Hopkins Marine Station, Stanford University, Pacific Grove, California 93950, USA \\ ${ }^{2}$ Ocean Sciences Department, University of California, Santa Cruz, California 95064, USA \\ ${ }^{3}$ Department of Ecology and Evolutionary Biology, Institute of Marine Science, Long Marine Lab, University of California, \\ Santa Cruz, California 95064, USA \\ ${ }^{4}$ Present address: Department of Wildlife, Fish, and Conservation Biology, University of California, Davis, California 95616, USA
}

\begin{abstract}
Electronic tags deployed on pelagic animals in the ocean are revolutionizing our understanding of how pelagic species interact with the physical environment, by making simultaneous ecophysiological and in situ oceanographic measurements at relatively low cost. Pelagic animals with electronic tags are also increasingly being used as ocean sensing platforms. Here, we demonstrate the concept of estimating in situ chlorophyll concentration profiles from light level and depth data collected by electronic tags, using a bio-optical model. We assessed this concept by deploying electronic tags at 14 oceanographic stations in the Pacific Ocean, together with a fluorometer and Niskin bottles. In the euphotic zone, tag-estimated chlorophyll concentrations correlated significantly with simultaneous chlorophyll concentration measurements from filtered water samples $\left(\mathrm{R}^{2}=0.41, \mathrm{p}<\right.$ $0.0001)$ and a profiling fluorometer $\left(R^{2}=0.29, p<0.0001\right)$. Below the euphotic zone, peaks in the light attenuation profile corresponded to deep scattering layers, with a $17 \mathrm{~m} \mathrm{rms}$ difference between the deep scattering layer depths estimated by the tags and an Acoustic Doppler Current Profiler. In situ chlorophyll profiles were also derived from electronic tags deployed on Pacific bluefin tuna in Baja California waters, and found to be comparable to chlorophyll profiles in the World Ocean Database for the region and season. Although more research is needed to improve this approach, the results from both shipboard and Pacific bluefin tuna experiments indicate that light level attenuation profiles derived from electronic tags can be successfully used to estimate chlorophyll concentration profiles.
\end{abstract}

KEY WORDS: Light level · Archival tag $\cdot$ Bio-optical model $\cdot$ Chlorophyll concentration estimation · Deep scattering layer $\cdot$ Pacific bluefin tuna $\cdot$ Thunnus orientalis

\section{INTRODUCTION}

The distribution of chlorophyll throughout the water column is one of the most important biological parameters in the ocean because it is an indicator of the spatial and temporal variability of primary productivity (Behrenfeld \& Falkowski 1997). In recent years, the increasing capabilities of electronic tags coupled with synoptic observations of the ocean surface from satellite-derived remote-sensing data have improved our understanding of the relationship between the spatio- temporal distribution of pelagic animals and various environmental parameters, including chlorophyll (Block et al. 2002, Costa et al. 2002, Polovina et al. 2004, Block et al. 2005, Weng et al. 2005, Biuw et al. 2007, Teo et al. 2007). For example, surface chlorophyll distributions estimated by satellite-based optical instruments like the Sea-viewing Wide Field-of-view Sensor (SeaWiFS) were integrated with the movement patterns of pelagic animals derived from electronic tag data to help understand this relationship (Polovina et al. 2004, Teo et al. 2007). 
However, these satellite-borne instruments perform poorly in areas with high cloud cover and/or seasonal ice coverage, and are not able to provide subsurface chlorophyll concentration profiles. Subsurface chlorophyll measurements have traditionally been made from research vessels, using profiling fluorometers and water samples collected by Niskin bottles. Alternatively, chlorophyll profiles can be obtained from fluorometers deployed on fixed moorings or autonomous platforms like Argo floats (Roemmich et al. 2004) and autonomous underwater vehicles (AUVs) (Yu et al. 2002). However, it remains relatively difficult and costly to coordinate research vessels and/or AUVs to sample an area at the same time as pelagic animals are observed to use the area, particularly over long durations (Baumgartner et al. 2003).

Since many pelagic animals dive repeatedly through the water column while traveling over long distances and electronic tags can measure oceanographic parameters at high sampling rates, the electronic tags deployed on pelagic animals can also act as low-cost in situ ocean sensing platforms. Thus, there is great interest in the biological and oceanographic research communities to maximize the use of oceanographic data collected under research programs utilizing electronic tags on animals (Boehlert et al. 2001, Fedak et al. 2001, Block et al. 2002, McMahon et al. 2005). Oceanographic parameters that can now be sampled by animal-borne electronic tags include temperature and salinity, but adding other parameters like chlorophyll is of great interest (Biuw et al. 2007, Charrassin et al. 2008). Ideally, electronic tags should incorporate fluorometers in order to obtain simultaneous estimates of chlorophyll in the water column as experienced by pelagic animals. However, there are few, if any, currently commercially available fluorometers with the appropriate size, weight and power consumption characteristics for incorporation into current electronic tags. It would especially be difficult to design fluorometers for use with pelagic fishes like tunas and sharks because the fluorometers would need to be orders of magnitude smaller than current instruments.

Here, we demonstrate an approach to estimate in situ chlorophyll concentrations from light and depth data collected by currently available geolocating electronic tags. Light and depth data are routinely collected by electronic tags to estimate the location of pelagic animals (Ekstrom 2004, Teo et al. 2004) but were not originally intended to be used to estimate chlorophyll concentrations. However, we can utilize these routinely collected data to estimate subsurface chlorophyll concentrations by first determining the water column's light attenuation profile from the light and depth data. We can then use a bio-optical model to derive chlorophyll estimates from the light attenuation profiles. This will allow us to obtain subsurface chlorophyll profiles along an animal's path while simultaneously observing part of the animal's behavior and physiology with the electronic tags. It also has the potential to greatly increase the number of in situ chlorophyll profiles available to the oceanographic community and hence improve our understanding of subsurface chlorophyll dynamics.

Our objectives in the present study were to assess the ability of commercially available electronic tags (LTD2310 archival tags, Lotek Wireless) to estimate subsurface chlorophyll concentrations in 2 ways: (1) in relatively controlled conditions by deploying the tags on an oceanographic carousel, and (2) in typical tag deployment conditions by deploying the tags on pelagic fish. Testing this approach by deploying tags on pelagic animals is important because changes in the orientation of the light sensor and/or animal during a dive may affect the light attenuation profiles due to changes in the optical geometry (Mobley 1994) and hence affect the accuracy and precision of the chlorophyll concentration estimates. To accomplish the first objective, we deployed the tags on a standard oceanographic carousel at stations in the tropical Pacific Ocean. Tag-derived chlorophyll concentration estimates were then compared with corresponding estimates from in situ water samples and a profiling fluorometer. Since light attenuation and acoustic echo intensity both tend to increase with increased biomass in the water column (Roe \& Griffiths 1993), we also hypothesized that the light attenuation profiles from the tags may be comparable to the echo intensity profiles from the shipboard Acoustic Doppler Current Profiler (ADCP). Therefore, we also compared the light attenuation profiles from the electronic tags with corresponding echo intensity profiles from the ADCP at the same stations. To accomplish the second objective, we deployed similar archival tags on Pacific bluefin tuna Thunnus orientalis in the eastern tropical Pacific Ocean. After recovering the archival tags, tag-derived chlorophyll concentration estimates were compared with records from the World Ocean Database (WOD) for the same season and location.

\section{MATERIALS AND METHODS}

Electronic tags. Standard LTD2310 archival tags (16 $\mathrm{mm} \varnothing, 76 \mathrm{~mm}$ length, $45 \mathrm{~g}$ in air; Lotek Wireless) measure and record relative light level, pressure, water temperature, and, during the bluefin tuna experiments, also body temperature. Pressure measurements were converted into depth data by assuming 1 decibar was approximately $0.993 \mathrm{~m}$. The tag has a sensor stalk (user-specified length) that contains a Teflon-coated 
optical fiber that is doped with fluorescent dye and channels light to the photodiode light sensor in the tag body. The sensor stalk is highly flexible and is coated with a black, opaque layer except for an optical window near the end of the stalk, which allows light to reach the optical fiber. The excitation spectrum of the fluorescent dye is used as an optical filter with an acceptance band centered on $470 \mathrm{~nm}$ (Ekstrom 2004). The acceptance band has a nominal bandwidth of $50 \mathrm{~nm}$ and a sharp edge at approximately $500 \mathrm{~nm}$. In pure water, blue light at $450 \mathrm{~nm}$ has the lowest attenuation coefficient $\left(0.018 \mathrm{~m}^{-1}\right)$ within the visible light spectrum (Morel \& Prieur 1977). The acceptance band of $470 \mathrm{~nm}$ was chosen during the development of the tag to reduce the attenuation of light with increasing depth and hence improve the ability to detect light at depth (Ekstrom 2004). The tip of the sensor stalk contains a thermistor that measures the water temperature, and the tag body contains a pressure sensor and a body temperature sensor. In a typical deployment in a tuna, the tag body is surgically implanted into the peritoneal cavity of the fish so that the sensor stalk protrudes through the body wall into the water column (Block et al. 1998). Placement of the tag in the peritoneal cavity of an endothermic animal also keeps the tag at a relatively stable and warm temperature, which may help stabilize the electronics.

The LTD2310 sensor stalk can be regarded as a cylindrical light collector; in a typical deployment on a fish, the flexible stalk will change its orientation rapidly with respect to the ambient light field as the fish moves through the water column. Therefore, we considered the tag-measured irradiance, $E_{\text {tag, }}$ to approximate the scalar irradiance at $470 \mathrm{~nm}, E_{0}$. Irradiance values are recorded by the tag as integers on a logarithmic scale that has nominally 32 units change in reading per order of magnitude change in irradiance (Ekstrom 2004). However, subsequent calibrations of the tags used in the present study showed that the logarithmic scale ranged from 36 to 37 units change per order of magnitude change in irradiance. It is important to note that the LTD2310 tag was designed to measure relative light levels and not absolute light levels. The light level measurements from the tags are therefore not calibrated to absolute levels of irradiance $\left(\mathrm{W} \mathrm{m}^{-2}\right)$, and light levels recorded by one tag may be different from another tag. However, this is not critical because our approach is to use the change of relative light level over depth to calculate the rate of light attenuation in the water column (see 'Model' subsection below for more details). For each tag, the logarithmic scale of the light level readings is verified by the manufacturer to be constant over the entire usable irradiance range ( 10 orders of magnitude) (Ekstrom 2004). The light sensor is also temperature compen- sated so that the irradiance values above the sensitivity threshold do not change with temperature. However, the sensitivity threshold varies by up to 1.5 orders of magnitude with changes in temperature (Ekstrom 2004). All irradiance values below the sensitivity threshold are flagged by the onboard processor and removed prior to analysis.

Model. We used a modified version of the bio-optical model developed by Morel (1988) to convert the irradiance values measured by the tags, $E_{\text {tag, into chloro- }}$ phyll concentration estimates, $C_{\text {tag }}$. Morel (1988) showed that the wavelength-specific diffuse attenuation coefficients of downward irradiance, $K_{\mathrm{d}}$, of surface Case-I waters can be related to the corresponding chlorophyll concentrations, $C$, by:

$$
K_{\mathrm{d}} \approx K_{\mathrm{dw}}+\chi C^{\mathrm{e}}
$$

where $K_{\mathrm{dw}}$ is the wavelength-specific diffuse attenuation of downward irradiance due to pure seawater, and $\chi$ and e are wavelength-specific fitted constants.

The $K_{\mathrm{d}}$ of the water column is defined as:

$$
K_{\mathrm{d}}=-\frac{1}{E_{\mathrm{d}}} \frac{\mathrm{d} E_{\mathrm{d}}}{\mathrm{d} z}
$$

where $z$ is the depth of the irradiance measurement and $E_{\mathrm{d}}$ is the downward irradiance. However, since the LTD2310 tag records relative irradiance values as integers on a logarithmic scale that had nominally 32 units change in reading per order of magnitude change in irradiance, we rearranged Eq. (2) and calculated the diffuse attenuation coefficient of tag-measured irradiance, $K_{\text {tag }}$, by:

$$
K_{\mathrm{tag}, z}=1-10^{\left[\frac{E_{\mathrm{tag}, z+1}-E_{\mathrm{tag}, z}}{D}\right]}
$$

where $K_{\mathrm{tag}, z}$ is the $K_{\mathrm{tag}}$ at depth $z, D$ is the number of units change in the $E_{\text {tag }}$ reading per order magnitude change in irradiance, and $E_{\mathrm{tag}, z}$ and $E_{\mathrm{tag}, z+1}$ are the interpolated irradiance values at depths $z$ and $z+1$, respectively. The raw $E_{\text {tag }}$ values were first interpolated with respect to depth using a loess fit (Cleveland 1993). An example from our shipboard experiments (described in 'Shipboard experiments') is shown in Fig. 1A. For each $1 \mathrm{~m}$, the interpolated $E_{\mathrm{tag}, z}$ and $E_{\text {tag, } z+1}$ were then used to calculate $K_{\text {tag }}$ from Eq. (3) (Fig. 1B). If we obtained a calibrated $D$ value from the manufacturer for the tag, we would use the calibrated value. However, if the calibrated $D$ value was not available for a particular tag, we parameterized $D$ with a value of 37 because the mean $D$ of the calibrated tags was $37 \pm 1$. By rearranging Eq. (1) and replacing constants $K_{\mathrm{dw}}, \chi$ and e with values for $470 \mathrm{~nm}$ (Morel 1988), we estimated the chlorophyll concentration $C_{\text {tag }}$ from $K_{\text {tag }}$ for each $1 \mathrm{~m}$ bin. The $C_{\text {tag }}$ values from all the depth bins were then collated to provide the tag- 

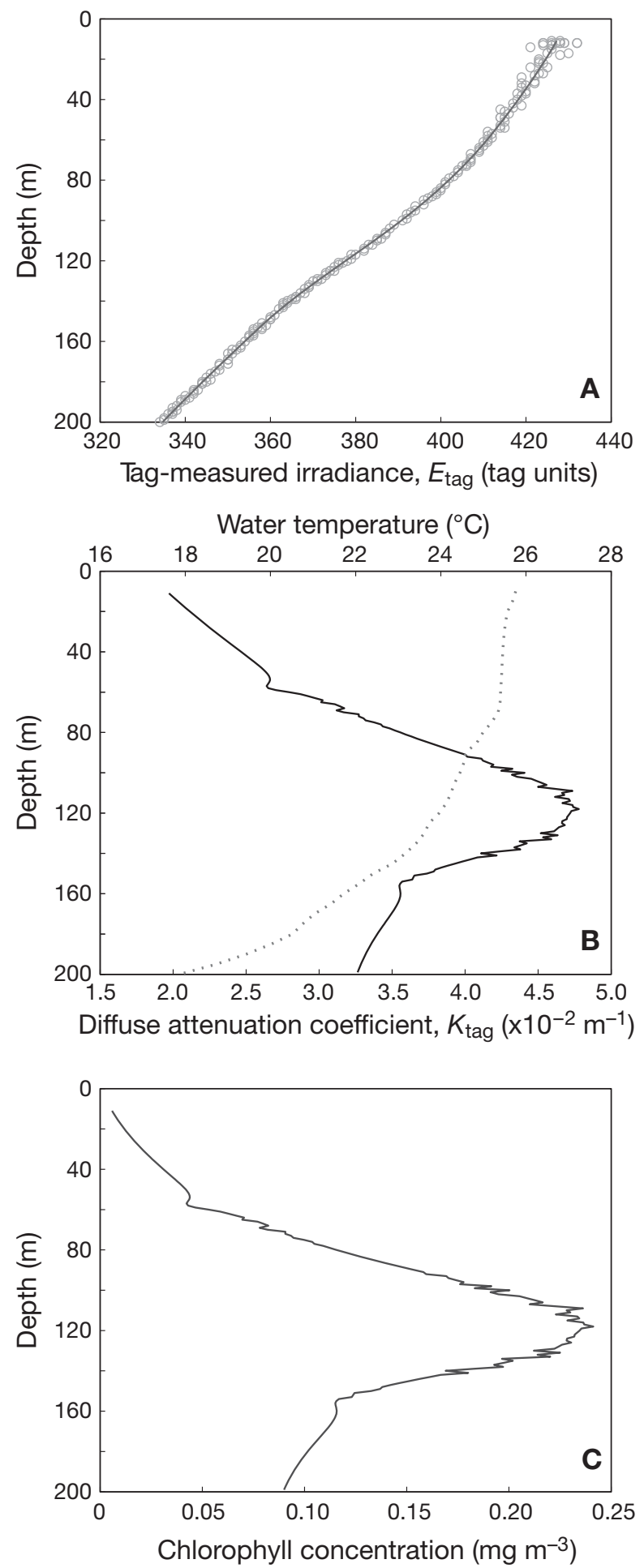

Fig. 1. Irradiance, diffuse attenuation coefficient and chlorophyll profiles from the upper $200 \mathrm{~m}$ at Stn S187-045 in 2003, using tag A0586. (A) Irradiance $\left(E_{\text {tag }}\right)$ measured by tag A0586 (grey circles) and interpolated irradiance profile calculated using a loess fit (solid line). (B) Water temperature profile (dotted line) and the diffuse attenuation coefficient profile of tag-measured irradiance, $K_{\text {tag }}$ (black line), which was calculated from the interpolated irradiance profile. (C) Tagestimated chlorophyll profile, using Eq. (1) estimated chlorophyll profile (Fig. 1C). This model was coded in Matlab (Matlab R14SP3, Mathworks).

Although the tag measures scalar irradiance rather than downward irradiance, computer simulations show that $K_{\mathrm{d}}$ is well approximated by the diffuse attenuation coefficient of scalar irradiance, $K_{\mathrm{o}}\left(K_{\mathrm{o}} / K_{\mathrm{d}}=1.01\right.$ to 1.06), for natural values of scattering and absorbance in the water column (Kirk 1994). Therefore, we expect to overestimate the chlorophyll concentration by up to $6 \%$ due to our use of scalar rather than downward irradiance. However, this source of error would not change the shape of the profile substantially because it affects the estimates equally. We consider this level of error to be acceptable because our aim in this study is to demonstrate the feasibility of this approach and approximate the relative chlorophyll profile to the first-order. With further improvements to this approach, we believe that the errors can and will be reduced substantially. We detail the likely sources of error and their effects in the discussion

Shipboard experiments. In 2003 and 2005, we assessed the ability of LTD2310 tags to estimate chlorophyll concentrations during oceanographic cruises on the SSV 'Robert C. Seamans'. Each cruise consisted of a roundtrip between Oahu, Hawaii, and Palmyra Atoll, with 7 oceanographic stations (Fig. 2). At each station, we attached 2 LTD2310 tags (programmed to record every $4 \mathrm{~s}$ ) to the top of the water-sampling carousel (SBE 32-16, Seabird Electronics), with the sensor stalk protruding into the water column. During a typical deployment on a pelagic fish, the sensor stalk protrudes into the water column from the side of the fish. The orientation of the sensor stalk on the carousel approximated the orientation during a typical deployment on a fish. Our aim for this set of experiments was to assess our approach under relatively controlled conditions with fewer changes in optical orientation than would be expected for the deployments on pelagic fish (see 'Materials and Methods - Pacific bluefin tuna experiments'). The carousel was equipped with 122.51 Niskin bottles (General Oceanics) and an SBE-19plus CTD profiler (Seabird Electronics) with an attached in situ chlorophyll fluorometer (SCF, Seapoint Sensors). Oceanographic sampling was conducted at approximately local noon and had maximum depths of $534 \pm$ $50 \mathrm{~m}$ (Table 1).

After each cast, the light attenuation $\left(K_{\text {tag }}\right)$ and chlorophyll concentration $\left(C_{\mathrm{tag}}\right)$ estimates for each tag were calculated using the method described above, and vertical profiles were constructed from these values. The $C_{\text {tag }}$ profiles in the euphotic zone for each station were compared to the chlorophyll profiles from the fluorometer and the water samples taken using the Niskin bottles. We only compared chlorophyll profiles in the euphotic zone because all chlorophyll maxima 


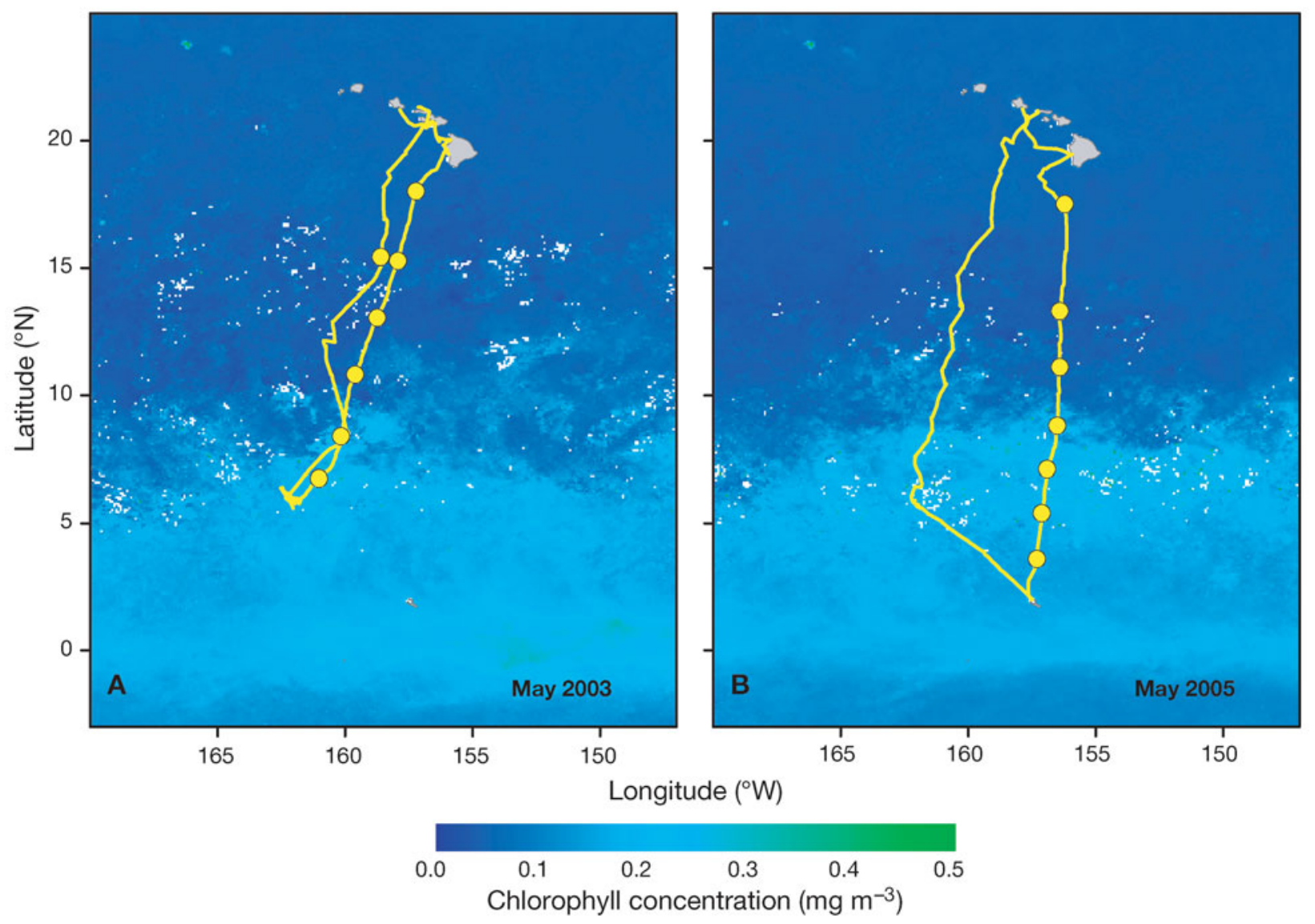

Fig. 2. Cruise track of SSV 'Robert C. Seamans' in (A) May 2003, Cruise S187 and (B) May 2005, Cruise S199. Mean surface chlorophyll concentrations for the corresponding month and year are shown. Circles indicate locations of oceanographic stations; white areas indicate clouds and/or missing data; grey areas indicate land

Table 1. Locations and dates of oceanographic stations during cruises in 2003 and 2005 on the SSV 'Robert C. Seamans'. Start time is in Hawaiian Standard Time

\begin{tabular}{|lccccc|}
\hline Date & $\begin{array}{c}\text { Start } \\
\text { time }\end{array}$ & Stn ID & $\begin{array}{c}\text { Longitude } \\
\left({ }^{\circ} \mathrm{W}\right)\end{array}$ & $\begin{array}{c}\text { Latitude } \\
\left({ }^{\circ} \mathrm{N}\right)\end{array}$ & $\begin{array}{c}\text { Depth of } \\
\text { cast }(\mathrm{m})\end{array}$ \\
\hline 2003 & & & & & \\
14 May & $11: 11$ & $\mathrm{~S} 187-014$ & 157.218 & 18.005 & 552 \\
15 May & $11: 17$ & $\mathrm{~S} 187-016$ & 157.920 & 15.272 & 434 \\
16 May & $11: 27$ & $\mathrm{~S} 187-018$ & 158.728 & 13.045 & 497 \\
17 May & $11: 11$ & $\mathrm{~S} 187-021$ & 159.598 & 10.803 & 460 \\
18 May & $11: 31$ & $\mathrm{~S} 187-023$ & 160.155 & 8.388 & 637 \\
19 May & $11: 11$ & $\mathrm{~S} 187-026$ & 161.012 & 6.737 & 589 \\
5 Jun & $11: 23$ & $\mathrm{~S} 187-045$ & 158.600 & 15.428 & 530 \\
& & & & & \\
2005 & & & & & \\
14 May & $12: 06$ & $\mathrm{~S} 199-010$ & 156.080 & 15.647 & 521 \\
15 May & $12: 00$ & $\mathrm{~S} 199-013$ & 156.375 & 13.328 & 560 \\
16 May & $11: 40$ & $\mathrm{~S} 199-016$ & 156.375 & 11.093 & 560 \\
17 May & $11: 56$ & $\mathrm{~S} 199-020$ & 156.513 & 8.842 & 517 \\
18 May & $12: 32$ & $\mathrm{~S} 199-023$ & 156.858 & 7.103 & 547 \\
19 May & $12: 08$ & $\mathrm{~S} 199-026$ & 157.067 & 5.390 & 551 \\
20 May & $12: 00$ & $\mathrm{~S} 199-029$ & 157.298 & 3.647 & 556 \\
\hline
\end{tabular}

were within this zone and deep scattering layers affected the quality of irradiance profiles below the euphotic depth. The euphotic zone was defined as the zone between the surface and the euphotic depth, defined here as the penetration depth of $1 \%$ of surface irradiance. The mean euphotic depth of the stations was $142 \pm 25 \mathrm{~m}$. The irradiance data for the upper $10 \mathrm{~m}$ of the water column were not used to estimate $K_{\text {tag }}$ and $C_{\text {tag }}$ profiles because the bottom of the ship's hull was at approximately $5 \mathrm{~m}$ depth and the irradiance data at those depths $(<10 \mathrm{~m})$ were relatively noisy due to shading.

Water sample chlorophyll concentrations were determined using standard fluorometric analysis of acetone extracts of the filtered samples. Water samples collected using Niskin bottles were divided into 2 subsamples and filtered $\left(1000 \mathrm{~cm}^{3}\right.$ in 2003; 250 and $500 \mathrm{~cm}^{3}$ in 2005) onto glass fiber filters (Whatman GF/F, nominally $0.7 \mu \mathrm{m}$ ) using positive pressure. The filters were placed in a test tube, wrapped in aluminum foil and frozen in the dark. Chlorophyll was extracted from the filter with $7 \mathrm{ml}$ of HPLC grade acetone for $24 \mathrm{~h}$ in the dark. The pigment concentration was then analyzed by the fluorometric method (Yentsch \& Menzel 
1963) with a blanked and calibrated fluorometer (Turner Designs 10-AU). For each station and depth, we calculated the mean chlorophyll concentration from the 2 subsamples and compared that to corresponding $C_{\text {tag }}$ profiles. The $C_{\text {tag }}$ profiles were also compared with those made by the in situ chlorophyll fluorometer (Astheimer \& Haardt 1984). We correlated the $C_{\text {tag }}$ profiles with the chlorophyll concentrations from the water samples and the fluorometer and calculated the overall rms difference between the corresponding profiles. The rms differences in the chlorophyll maxima depths detected by the 3 methods were also calculated.

In addition, we used the ADCP $(75 \mathrm{kHz}$ Ocean Surveyor, RD Instruments) aboard the vessel to estimate the deep scattering layer depth and compared the ADCP's echo intensity profile with the $K_{\text {tag }}$ profile at the oceanographic stations. The acoustic backscatter strength of the water column is related to the biomass profile of the water column and the ADCP's echo intensity profile has been used to estimate the biomass of deep scattering layers (Flagg \& Smith 1989, Heywood et al. 1991, Griffiths \& Diaz 1996). Since light attenuation also increases with increased biomass in the water column, we hypothesized that the light attenuation profiles from the tags may be comparable to the echo intensity profiles from the shipboard ADCP. We set the ADCP software to aggregate the raw echo intensity of each acoustic beam into ensembles of $20 \mathrm{~min}$ and $10 \mathrm{~m}$ bins (60 bins, 18 to $608 \mathrm{~m}$ ). The echo intensity profiles of the 4 beams were then averaged to obtain the echo intensity profile of each ensemble. For each station, we selected the echo intensity profiles from 3 ensembles collected during the cast and compared the mean echo intensity profile with $K_{\text {tag }}$ profiles obtained by the tag. The deep scattering layer depth of each station was determined by the depth of the secondary peak of the echo intensity profile. We then calculated the rms difference between the deep scattering layer depths estimated by the ADCP and the tag.

Pacific bluefin tuna experiments. We also assessed this method by deploying 48 LTD2310 archival tags on Pacific bluefin tuna in the eastern tropical Pacific Ocean. The fish were caught by commercial purse seines and transferred by tow pens to grow-out pens on the Pacific coast of Baja California, Mexico. On 9 March 2005, the fish were brought up onto a vinyl surgical pad on the deck of a barge for surgery. Each bluefin tuna was measured (cm curved fork length [CFL]) and an LTD2310 archival tag was surgically implanted into the peritoneal cavity of the fish so that the sensor stalk protruded from the body of the fish (Block et al. 1998). The fish were immediately transferred to a tow pen that was towed offshore $\left(31.718^{\circ} \mathrm{N}\right.$, $116.997^{\circ} \mathrm{W}$ ) before the fish were released. All procedures were conducted in accordance with approved animal care protocols. The tags were programmed to sample every 4 or $8 \mathrm{~s}$. Since the LTD2310 tags were surgically implanted into the peritoneal cavity of the tuna, the fish had to be recaptured to retrieve the tag and the collected data.

Sixteen of the tagged bluefin tuna were subsequently recaptured by commercial fishers. For each day, we extracted the irradiance and pressure data from a period of $2 \mathrm{~h}$ surrounding the local noon to minimize variation of the ambient light field (see 'Discussion' for more details). Corresponding $C_{\text {tag }}$ values were estimated from the extracted irradiance and depth data using the method described above. Irradiance data from the upper $10 \mathrm{~m}$ were not used because the irradiance data at those depths were relatively noisy. Profiles with sparse data (<100 data points) or large spikes $\left(>2.0 \mathrm{mg} \mathrm{m}^{-3}\right)$ were eliminated before further analysis. Based on the WOD (www.nodc.noaa.gov) and our oceanographic casts in the area, this value is outside the $95 \%$ confidence interval of subsurface chlorophyll maxima concentrations recorded in the area. Individual chlorophyll profiles were smoothed with a robust, locally weighted least squares fit (Cleveland 1993). To visualize how the chlorophyll profiles from a single fish changed over time, we concatenated daily $C_{\text {tag }}$ profiles from the same fish into a single array and applied a 2-dimensional $3 \times$ 3 median filter to reduce noise in the array.

Geolocations of the Pacific bluefin tuna were estimated from light level longitude and sea surface temperature (SST) data recorded by the tags using a modification of the methods described by Teo et al. (2004). SST data from the tags were combined with corresponding light level longitude estimates to obtain daily latitude estimates. For a given day, the latitude at which the tag-recorded SSTs best matched the corresponding remotely sensed SSTs, along the light level longitude estimate, was considered the latitude estimate for the day. Based on swimming speeds estimated from acoustic tracking studies (Boustany et al. 2001), the SST matching process for each day was constrained to the area that the fish could have realistically moved. We also improved the geolocation algorithm with the addition of the capacity to switch to cloud-free, microwave-based, remotely sensed SST data (TMI/AMSRE, ftp:/ftp.discover-earth.org/sst/) during periods with high cloud cover, and an improvement to the algorithm used ensured the movement path did not cross land. Daily maximum diving depths recorded by the tags were also used to filter geolocation estimates so that the maximum diving depth did not exceed the known bathymetry (inclusive of error estimates) at the geolocation estimate for the corresponding day. Archival tags were found to have rms errors of $0.78^{\circ}$ and $0.90^{\circ}$ for longitude and latitude estimates, respectively (Teo et al. 2004). 
Mean depths of the chlorophyll maxima and mean chlorophyll concentrations at the maxima estimated from electronic tags were compared to the profiles recorded in the WOD for the season and region. Here, we used $C_{\text {tag }}$ profiles that went deeper than the euphotic depth to ensure that the profiles included the chlorophyll maxima. We extracted corresponding WOD chlorophyll profiles for the same month that were within $1^{\circ}$ of the geolocation estimate. However, the WOD profiles were typically from a different year. It was therefore not possible to determine the actual errors in the tag-derived chlorophyll estimates because the chlorophyll data from the WOD were from a different year and therefore not the actual chlorophyll concentration when the bluefin tuna was in the area. However, this was not critical because we did not set out to determine the error distribution of the chlorophyll estimates. Rather, our aim for this set of experiments was to determine if we could derive reasonable chlorophyll profiles for this area and season using these electronic tags. We assumed that the chlorophyll profiles in the WOD for the same season and region provided a reasonable range of chlorophyll maxima concentrations and depth likely to be experienced by the tuna. We subsequently calculated the overall rms differences between the chlorophyll maxima concentrations and depths from the tags and the WOD. In addition, we determined if the chlorophyll maxima concentration and depth of each profile were within the $95 \%$ confidence interval of the corresponding WOD mean chlorophyll maxima concentration and depth.

\section{RESULTS}

\section{Shipboard experiments}

In the euphotic zone, chlorophyll profiles estimated by the LTD2310 tags were representative of the oceanographic stations and were similar to the profiles measured from the fluorometer and water samples. As an example, the chlorophyll concentrations determined by all 3 methods at Stn S187-045 are shown in Fig. 3. Across all 14 stations, tag-estimated chlorophyll concentrations were significantly correlated with chlorophyll concentrations measured from the fluorometer $\left(\mathrm{R}^{2}=0.29, \mathrm{n}=142, \mathrm{p}<0.0001\right)$ and water samples $\left(\mathrm{R}^{2}=0.41, \mathrm{n}=142, \mathrm{p}<0.0001\right)$ (Fig. 4). However, there were clearly differences between the methods. Overall rms differences between the euphotic zone chlorophyll concentrations estimated by the tag versus corresponding chlorophyll concentrations measured from the filtered water samples and fluorometer were 0.088 and $0.27 \mathrm{mg} \mathrm{m}^{-3}(\mathrm{n}=142)$, respectively. This

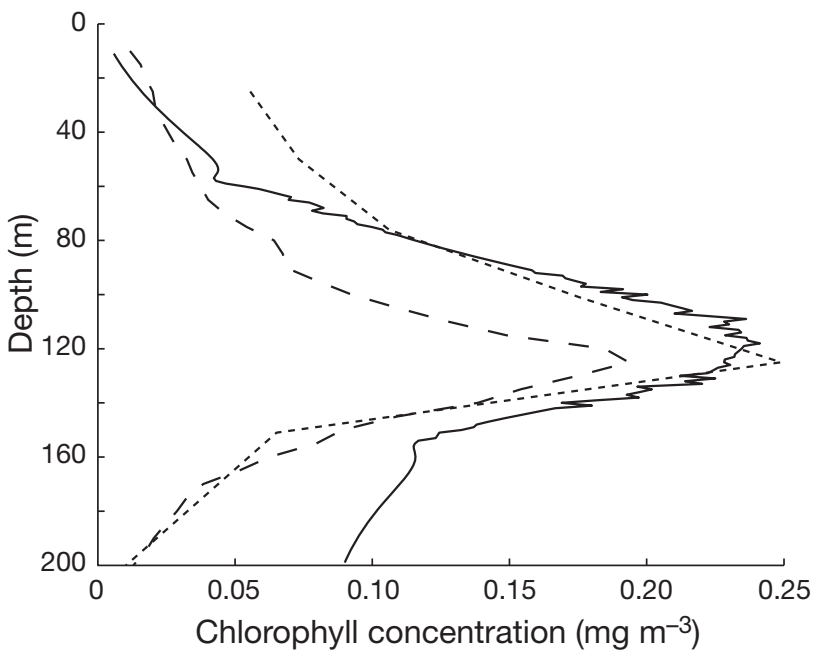

Fig. 3. Chlorophyll profiles from the upper $200 \mathrm{~m}$ at Stn S187045, using tag A0586 (-), filtered water samples (-..--) and profiling fluorometer (- - - )

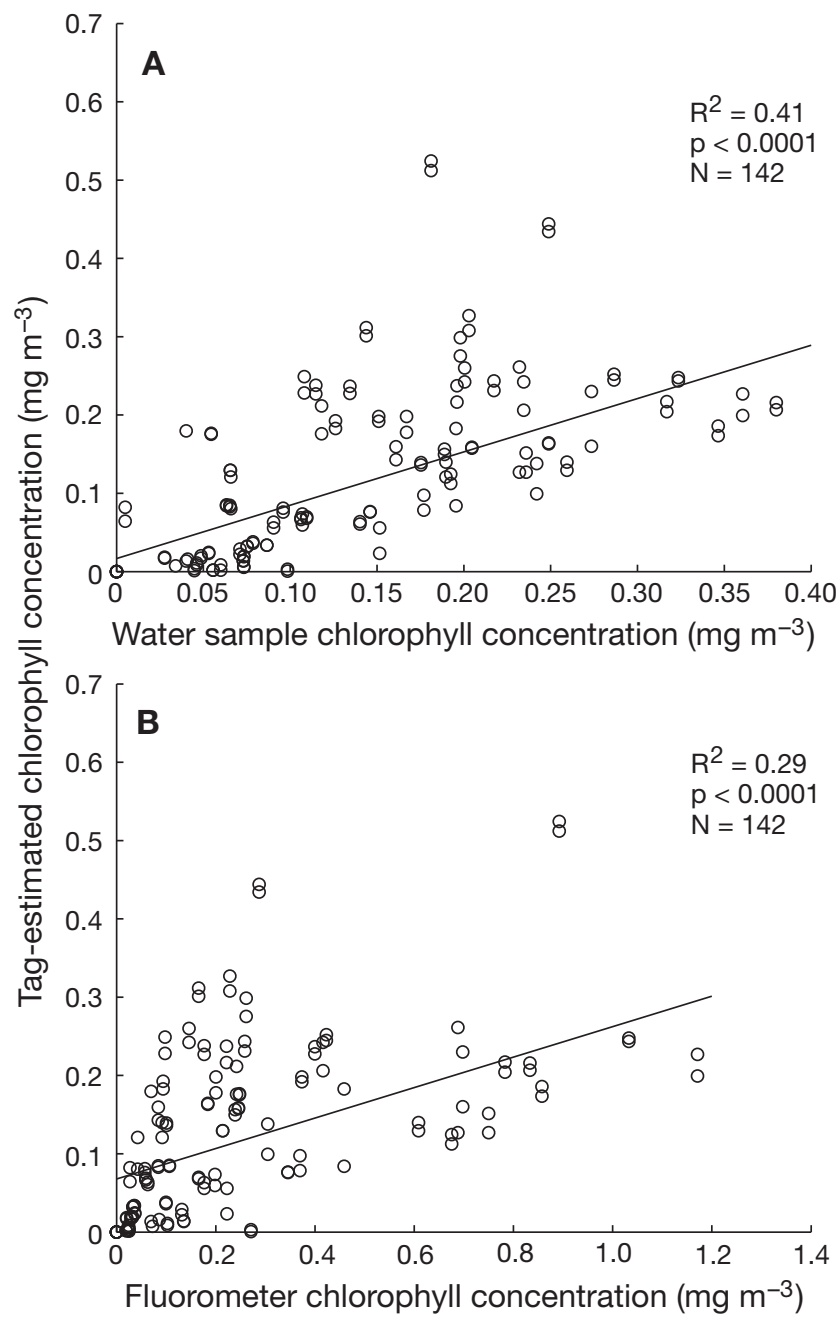

Fig. 4. Correlation of tag-estimated chlorophyll concentrations with (A) filtered water samples and (B) profiling fluorometer from all oceanographic stations 
compares well with the rms difference $\left(0.23 \mathrm{mg} \mathrm{m}^{-3}\right.$, $\mathrm{n}=142$ ) between corresponding chlorophyll concentrations measured from the filtered water samples and the fluorometer.

This method performed well overall during both cruises but it performed relatively poorly at one station during each cruise (S187-026 and S199-023). At both stations, the $C_{\text {tag }}$ profiles did not match the profiles measured from the water samples. Interestingly, both stations were at approximately the same latitude $\left(7^{\circ} \mathrm{N}\right)$ (Table 1), which was at the edge of the equatorial upwelling zone, and both stations had relatively shallow chlorophyll maxima.

Below the euphotic zone, the deep scattering layers influenced the $K_{\text {tag }}$ profile. The $K_{\text {tag }}$ profiles showed a large secondary peak below the euphotic zone even though there is only a negligible amount of chlorophyll at those depths (Fig. 5). These deeper peaks corresponded well to the depths at which the ADCP echo intensity increased (Fig. 5). The increased echo intensity indicates the presence of deep scattering layers and increased biomass at those depths (Flagg \& Smith 1989, Heywood et al. 1991). Based on the ADCP, the deep scattering layers during the oceanographic sta-

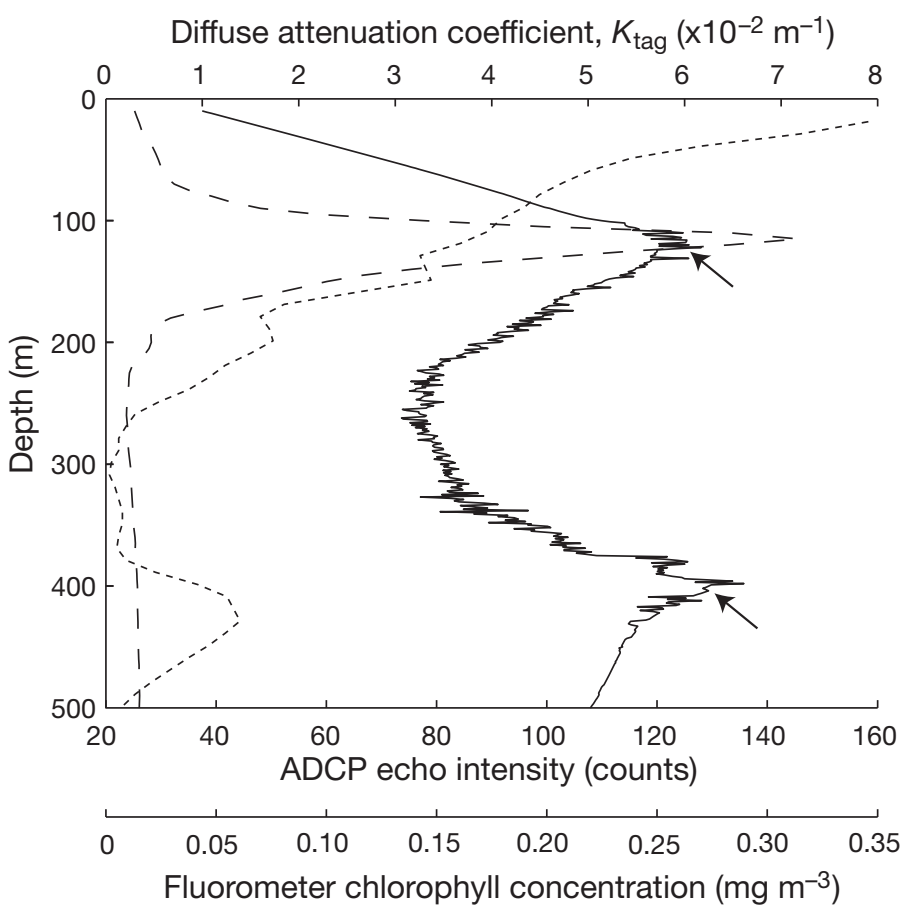

Fig. 5. Profiles of diffuse attenuation coefficients, $K_{\text {tag, }}$ estimated from tag C0300 (- ${ }_{-}$, chlorophyll concentrations estimated by the fluorometer (- - - ) and Acoustic Doppler Current Profiler (ADCP) echo intensity (--.--) at Stn S199-010. Arrows indicate peaks of $K_{\text {tag }}$ at this station, with the shallow peak coinciding with the chlorophyll maxima and the deep peak coinciding with a peak in ADCP echo intensity tions were at depths ranging from approximately 290 to $440 \mathrm{~m}$. The overall $\mathrm{rms}$ difference between the deep scattering layer depths estimated by the tags and the ADCP was $17 \mathrm{~m}$.

\section{Pacific bluefin tuna experiments}

For the Pacific bluefin tuna experiments, tag-estimated chlorophyll profiles were comparable to chlorophyll profiles recorded in the WOD for the region. As an example, the irradiance profile collected by bluefin tuna C0071 from 2 June 2005 was used to estimate the $K_{\text {tag }}$ and $C_{\text {tag }}$ profiles (Fig. 6A). The $C_{\text {tag }}$ profile was comparable to the WOD chlorophyll profiles in June that were within $1^{\circ}$ of the fish's geolocation (Fig. 6B).

Overall, chlorophyll profiles from the bluefin tuna had maximal chlorophyll concentrations and chlorophyll maxima depths that were similar to those recorded in the WOD for the Baja California region. The rms differences between the $C_{\text {tag }}$ at the chlorophyll maxima and the WOD chlorophyll profiles were 0.23 and $0.26 \mathrm{mg} \mathrm{m}^{-3}$ for tags sampling at every 4 and $8 \mathrm{~s}$, respectively. Most of the tag-estimated maximal chlorophyll concentrations $(91.8 \%$ for $4 \mathrm{~s}$ tags, $88.5 \%$ for $8 \mathrm{~s}$ tags) were also within the $95 \%$ confidence intervals of the WOD maximal chlorophyll concentrations. In addition, the rms differences in the chlorophyll maxima depths estimated by the tags and in the WOD were 25 and $26 \mathrm{~m}$ for the tags sampling at 4 and $8 \mathrm{~s}$, respectively. The majority of tagestimated chlorophyll maxima depths $(82.4 \%$ for $4 \mathrm{~s}$ tags, $73.0 \%$ for $8 \mathrm{~s}$ tags) were also within the $95 \%$ confidence intervals of the WOD chlorophyll maxima depths.

Daily chlorophyll profiles were concatenated to illustrate the changes in their chlorophyll profiles (see Fig. 6C for an example for bluefin tuna C0071). For instance, the mean chlorophyll concentration at the chlorophyll maxima for bluefin tuna C0071 was $0.45 \pm$ $0.08 \mathrm{mg} \mathrm{m}^{-3}$ and the mean chlorophyll maxima depth was $69 \pm 14 \mathrm{~m}$. Changes in the $C_{\text {tag }}$ profiles were compared to the corresponding horizontal movements, ambient temperature profiles and depth preferences (Fig. 7); however, a detailed analysis of this is beyond the scope of this paper. Depths of the chlorophyll maxima from bluefin tuna C0071 were significantly correlated with the thermocline depth $\left(\mathrm{R}^{2}=0.60, \mathrm{p}<\right.$ 0.0001). The correlation between the thermocline and the chlorophyll maxima depths adds to our confidence in the $C_{\text {tag }}$ profiles because the nutricline is closely related to the thermocline in the region and the chlorophyll profile is likely to be related to the nutricline depth (Wilson \& Coles 2005). 

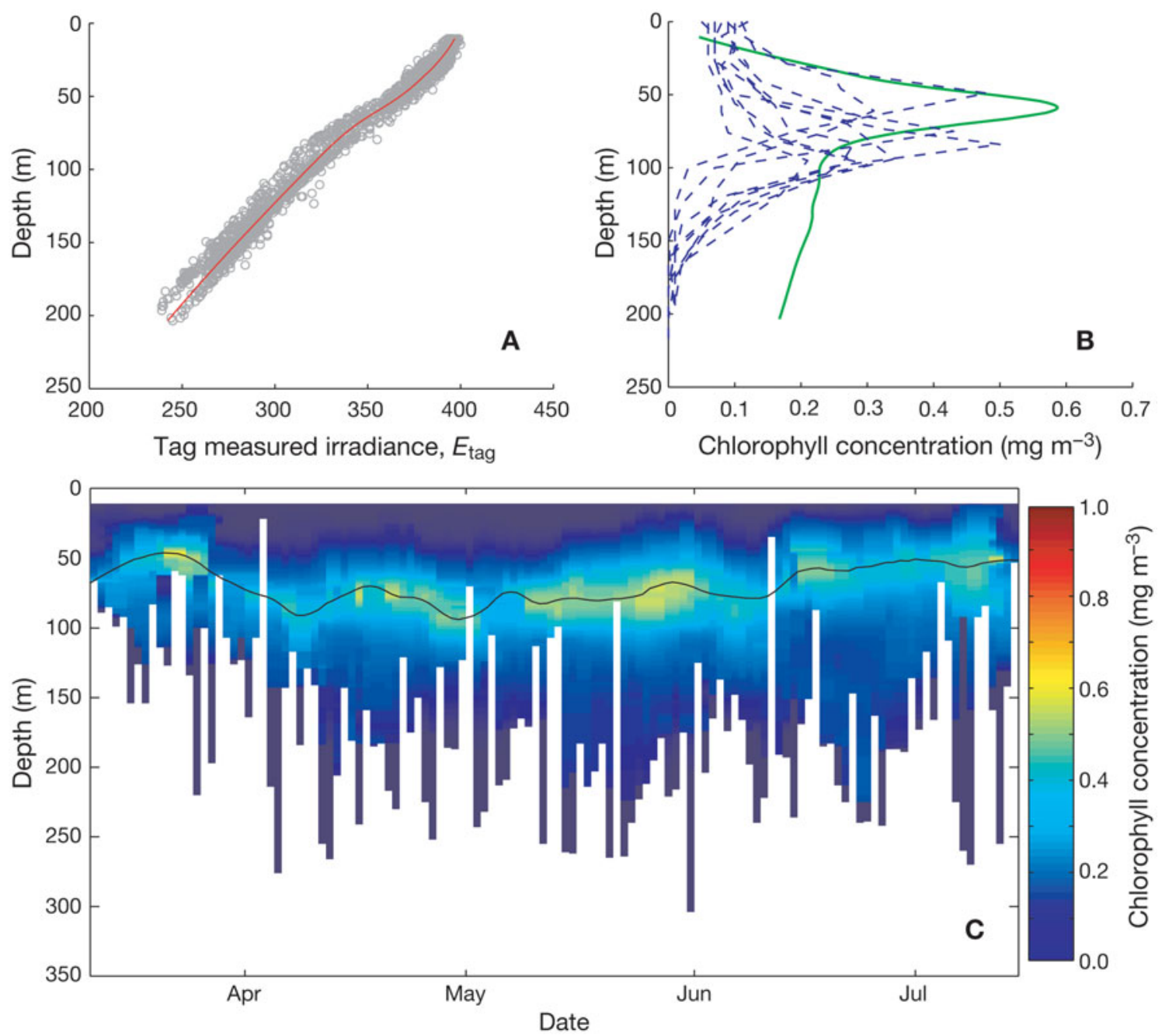

Fig. 6. Irradiance, ambient temperature and chlorophyll profiles estimated from Pacific bluefin tuna C0071 on 2 June 2005 off Baja California. (A) Irradiance ( $E_{\text {tag }}$ grey circles) and interpolated irradiance profile calculated using a loess fit (red line). (B) Chlorophyll profiles estimated from the tag (green) and in the World Ocean Database for the month of June and within $1^{\circ}$ of the fish's estimated geolocation for 2 June 2005 (dashed lines). (C) Chlorophyll profiles of Pacific bluefin tuna C0071 from 11 March to 15 July 2005. Black line indicates depth of chlorophyll maxima

\section{DISCUSSION}

In the present study, we have demonstrated the concept of using light level and depth data from geolocating electronic tags deployed on pelagic animals to obtain in situ chlorophyll profiles. Although there clearly remains much more work to be done to improve the accuracy and precision of the chlorophyll estimates, our results suggest that the approach is promising. With further refinements to this approach, research programs utilizing electronic tags can maximize the use of oceanographic data collected by these tags. One potential use will be to obtain subsurface chlorophyll profiles along an animal's path while simultaneously observing the animal's behavior and physiology, which will likely improve our understanding of the relationship between pelagic animals and the deep chlorophyll maxima. In addition, it also has the potential to greatly increase the number of in situ chlorophyll profiles available to the oceanographic community and, hence, improve our understanding of subsurface chlorophyll dynamics.

One of the important sources of error is variability in the ambient light field. If the ambient light field is rapidly changing, any change in the irradiance profile might reflect ambient light field changes rather than light attenuation. To reduce the influence of ambient light field variability, we only used data from a $2 \mathrm{~h}$ period around the local noon, which improves the accuracy and reduces the variability of the $K_{\text {tag }}$ and, hence, the $C_{\text {tag }}$ profiles. Since the rate of change of solar irradiance is at its slowest during local noon, this 

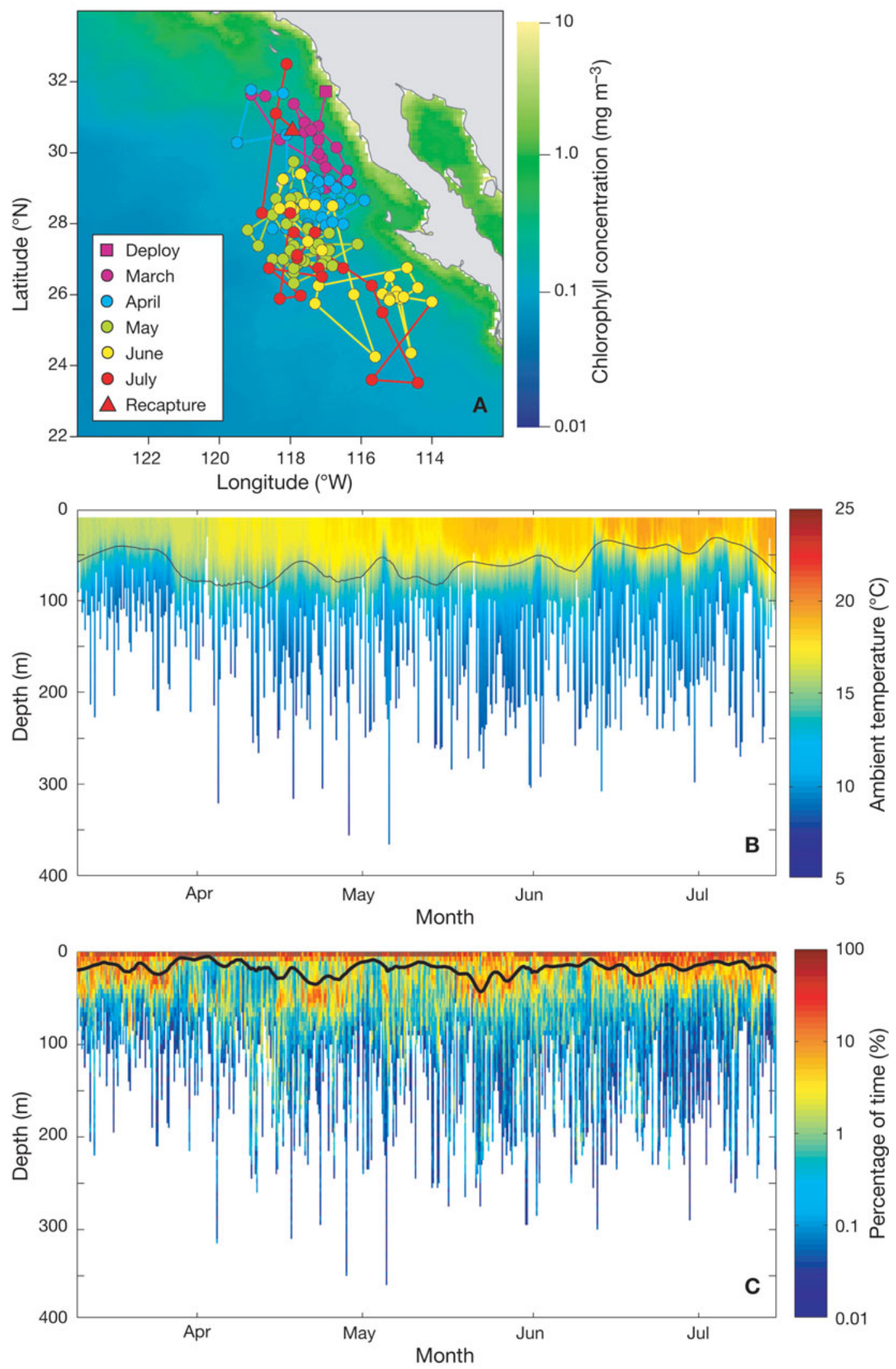

Fig. 7. (A) Horizontal movements. Monthly horizontal movements are shown with mean chlorophyll concentrations for 2005; (B) ambient temperature profiles (black line indicates thermocline depth); and (C) depth preferences of Pacific bluefin tuna C0071 from 11 March to 15 July 2005 (black line indicates mean depth) 
would reduce ambient light field changes and hence improve the $K_{\text {tag }}$ and $C_{\text {tag }}$ profiles. The high solar elevation angle during local noon also reduces the effect of changing atmospheric conditions because the apparent atmospheric optical thickness is reduced. In addition, the high solar elevation angle reduces the reflectance and diffraction of light at the air-sea interface due to Snell's law and the irradiance profile in the water is less influenced by a changing sea state (Kirk 1994). Another advantage is that the solar irradiance, for a given day and set of conditions, is maximal during local noon, which would increase the penetration depth of light and hence the depth range for which this method is effective.

Diving behavior of the animal also interacts with the tag's optical geometry to affect our ability to estimate chlorophyll profiles. Here, we used the LTD2310 tag, which has a flexible cylindrical light collector that protrudes into the water column and moves around rapidly as the animal swims. Hence, the tag can be assumed to measure overall scalar irradiance (i.e. measuring light equally from all directions). Therefore, the angle at which the photons intercept the light sensor does not affect the tag's irradiance measurement. On the other hand, cosine collectors (flat light sensors that face upwards or downwards) are sensitive to the angle at which the photons intercept the light collector. Therefore, tags with cosine collectors are more likely to be sensitive to changes in the tag's orientation during an animal's dive. If the orientation of the animal during a dive is relatively random, changes in the optical geometry should equal out over time. However, if the animal's orientation changes in a regular fashion during specific parts of the dive, it would be important to correct the irradiance data for body orientation.

For this method to be effective when the pelagic animals are moving rapidly over large spatial scales at relatively short temporal scales, it will likely require modifications to the algorithm described here. When pelagic animals are moving rapidly, the animal may be moving through several water masses within a short time period. Therefore, the light attenuation profile data from a single day may consist of a mixture of light attenuation profiles from different water masses. One possible way to tackle this problem would be to focus the analysis on an individual dive over a short time period. In this way, the chance of the data being from multiple water masses is reduced. The drawback of this approach, however, is that the tag would need to be sampling at very high rates for there to be enough light and depth data for analysis.

The relatively poor performance of this method at the oceanographic stations close to the upwelling zone suggests the need for potential improvements to the current method. In addition to increased primary pro- ductivity, upwelling zones also tend to have increased secondary productivity, especially near the edges of the upwelling zones (Cury \& Roy 1989). The increased zooplankton abundance in upwelling areas may have led to a reduction in the performance of Morel's (1988) bio-optical model, which was parameterized for Case-I (open ocean) waters. One way to improve the future performance of this method is to measure the irradiance and attenuation at multiple optical bands, rather than a single optical band. For example, the ratio between the remote sensing reflectance at 490 and $555 \mathrm{~nm}$ is used in empirical and semianalytic biooptical models to estimate the surface chlorophyll content from remote sensing data (O'Reilly et al. 1998). Since the remote sensing reflectance at a specific wavelength is related to $K_{\mathrm{d}}$ (Mobley 1994), we will be able to use a similar multi-band approach to estimate chlorophyll profiles from electronic tags. Indeed, we are currently testing the use of dual-band tags on northern elephant seals to estimate chlorophyll profiles. These multi-band instruments will also allow us to use new bio-optical algorithms developed for passive optical sensors deployed on AUVs and Argo floats (Brown et al. 2004).

Besides Morel (1988), there are alternative bio-optical models that can be used with electronic tags and it would be useful to compare the performance of these different models in future studies. However, it would be important that the details of each model be understood and found to be applicable for the study. For example, Morel \& Maritorena (2001) used new optical data from several Joint Global Ocean Flux Study (JGOFS) cruises to revise Morel's (1988) bio-optical model. However, we were unable to use those results in the present study because the in situ chlorophyll concentrations from the JGOFS cruises were primarily measured using HPLC (Morel \& Maritorena 2001). In contrast, the chlorophyll concentration data from Morel (1988) were primarily determined using fluorometric methods, which were similar to the methods used in the present study. In addition, it would be useful to compare the performance of electronic tags from different manufacturers under different environmental conditions. Since the optics and electronics of tags from different manufacturers can differ substantially, we expect that this may result in differing abilities to estimate chlorophyll concentrations.

Bio-optical models are typically developed for surface waters, but we showed that $K_{\text {tag }}$ profiles below the euphotic zone might be used to estimate deep scattering layer depths. The $K_{\text {tag }}$ profiles often showed a large secondary peak below the euphotic zone even though there was only a minimal amount of chlorophyll at those depths. These deeper peaks corresponded to the depths at which ADCP echo intensity increased 
(Fig. 5), suggesting that scattering and absorbance of light by animals in the deep scattering layers were detected by the tags. However, caution should be used in interpreting this result because the irradiance levels at these depths were approaching the detection limit of this generation of tags. We speculate that the next generation of tags, with potentially 2 to 3 more orders of magnitude of sensitivity to light, might be used to validate the ability to estimate deep scattering layer depths. In addition, it would be important to test this by deploying tags on species that are associated with the deep scattering layer and dive repeatedly through the water column during the day, e.g. bigeye tuna and elephant seals (Dagorn et al. 2000, Le Boeuf et al. 2000, Campagna et al. 2001, Schaefer \& Fuller 2002). In the future, it would also be interesting to correlate the biomass at these depths with the $K_{\text {tag }}$ profiles obtained from the tags. This would enable us to estimate the deep scattering layer biomass with these tags and allow us to determine if long-term changes in diving behavior are related to changes in the deep scattering layer depth and biomass. Currently, we have to deploy ships or AUVs to obtain acoustic profiles or net samples of the deep scattering layer at the same time as the animal is being tracked (Dagorn et al. 2000).

Acknowledgements. We thank all participants of the workshops organized by the Tagging of Pacific Pelagics (TOPP) project, especially S. Simmons, for discussions that led to this study, as well as the captain, crew, instructors and students of the Stanford@SEA classes on the SSV 'Robert C. Seamans' for their enthusiasm and assistance in data collection. We particularly thank J. Witting, K. Lavendar and R. Dunbar for their help on these cruises. We would also like to thank members of the Block Lab for helping us tag bluefin tuna in Baja California, especially C. Farwell and T. Williams. Five anonymous reviewers provided comments that improved the manuscript. Funding was provided by the David and Lucile Packard, Alfred P. Sloan and Gordon and Betty Moore Foundations.

\section{LITERATURE CITED}

Astheimer H, Haardt H (1984) Small-scale patchiness of the chlorophyll fluorescence in the sea: aspects of instrumentation, data processing, and interpretation. Mar Ecol Prog Ser 15:233-245

Baumgartner MF, Cole TVN, Campbell RG, Teegarden GJ, Durbin EG (2003) Associations between North Atlantic right whales and their prey, Calanus finmarchicus, over diel and tidal time scales. Mar Ecol Prog Ser 264:155-166

Behrenfeld MJ, Falkowski PG (1997) Photosynthetic rates derived from satellite-based chlorophyll concentration. Limnol Oceanogr 42:1-20

Biuw M, Boehme L, Guinet C, Hindell M and others (2007) Variations in behavior and condition of a Southern Ocean top predator in relation to in situ oceanographic conditions. Proc Natl Acad Sci USA 104:13705-13710

Block BA, Dewar H, Williams T, Prince ED, Farwell C, Fudge
D (1998) Archival tagging of Atlantic bluefin tuna (Thunnus thynnus thynnus). Mar Technol Soc J 32:37-46

Block B, Costa D, Boehlert G, Kochevar R (2002) Revealing pelagic habitat use: the tagging of Pacific pelagics program. Oceanol Acta 25:255-266

Block BA, Teo SLH, Walli A, Boustany A and others (2005) Electronic tagging and population structure of Atlantic bluefin tuna. Nature 434:1121-1127

Boehlert GW, Costa DP, Crocker DE, Green P, O'Brien T, Levitus S, Le Boeuf BJ (2001) Autonomous pinniped environmental samplers: using instrumented animals as oceanographic data collectors. J Atmos Ocean Technol 18:1882-1893

Boustany A, Marcinek DJ, Keen JE, Dewar H, Block BA (2001) Movements and temperature preference of Atlantic bluefin tuna (Thunnus thynnus) off North Carolina: a comparison of acoustic, archival and pop-up satellite tagging. In: Sibert JR, Nielsen JL (eds) Electronic tagging and tracking in marine fishes. Kluwer Academic Publishers, Dordrecht, p 89-108

Brown CA, Huot Y, Purcell MJ, Cullen JJ, Lewis MR (2004) Mapping coastal optical and biogeochemical variability using an autonomous underwater vehicle and a new biooptical inversion algorithm. Limnol Oceanogr Methods 2: 262-281

Campagna C, Dignani J, Blackwell SB, Marin MR (2001) Detecting bioluminescence with an irradiance time-depth recorder deployed on southern elephant seals. Mar Mamm Sci 17:402-414

Charrassin JB, Hindell M, Rintoul SR, Roquet F and others (2008) Southern Ocean frontal structure and sea-ice formation rates revealed by elephant seals. Proc Natl Acad Sci USA 105:11634-11639

Cleveland WS (1993) Visualizing data. Hobart Press, Summit, NJ

Costa DP, Crocker DE, Boehlert G (2002) Foraging behavior of northern elephant seals relative to frontal features in the North Pacific Ocean. Integr Comp Biol 42:1212-1212

Cury P, Roy C (1989) Optimal environmental window and pelagic fish recruitment success in upwelling areas. Can J Fish Aquat Sci 46:670-680

Dagorn L, Bach P, Josse E (2000) Movement patterns of large bigeye tuna (Thunnus obesus) in the open ocean, determined using ultrasonic telemetry. Mar Biol 136:361-371

Ekstrom PA (2004) An advance in geolocation by light. In: Naito Y (ed) Memoirs of the National Institue of Polar Research, Special Issue, Vol 58. National Institute of Polar Research, Tokyo, p 210-226

Fedak MA, Lovell P, Grant SM (2001) Two approaches to compressing and interpreting time-depth information as collected by time-depth recorders and satellite-linked data recorders. Mar Mamm Sci 17:94-110

Flagg CN, Smith SL (1989) On the use of the Acoustic Doppler Current Profiler to measure zooplankton abundance. Deep-Sea Res A 36:455-474

Griffiths G, Diaz JI (1996) Comparison of acoustic backscatter measurements from a ship-mounted Acoustic Doppler Current Profiler and an EK500 scientific echo-sounder. ICES J Mar Sci 53:487-491

Heywood KJ, Scropehowe S, Barton ED (1991) Estimation of zooplankton abundance from ship-borne ADCP backscatter. Deep-Sea Res A 38:677-691

Kirk JTO (1994) Light and photosynthesis in aquatic ecosystems. Cambridge University Press, Cambridge

> Le Boeuf BJ, Crocker DE, Costa DP, Blackwell SB, Webb PM, Houser DS (2000) Foraging ecology of northern elephant seals. Ecol Monogr 70:353-382 
McMahon CR, Autret E, Houghton JDR, Lovell P, Myers AE, Hays GC (2005) Animal-borne sensors successfully capture the real-time thermal properties of ocean basins. Limnol Oceanogr Methods 3:392-398

Mobley CD (1994) Light and water: radiative transfer in natural waters. Academic Press, San Diego, CA

Morel A (1988) Optical modeling of the upper ocean in relation to its biogenous matter content (Case-I waters). J Geophys Res C 93:10749-10768

Morel A, Maritorena S (2001) Bio-optical properties of oceanic waters: a reappraisal. J Geophys Res C 106:7163-7180

Morel A, Prieur L (1977) Analysis of variations in ocean color. Limnol Oceanogr 22:709-722

O'Reilly JE, Maritorena S, Mitchell BG, Siegel DA and others (1998) Ocean color chlorophyll algorithms for SeaWiFS. J Geophys Res C 103:24937-24953

Polovina JJ, Balazs GH, Howell EA, Parker DM, Seki MP, Dutton PH (2004) Forage and migration habitat of loggerhead (Caretta caretta) and olive ridley (Lepidochelys olivacea) sea turtles in the central North Pacific Ocean. Fish Oceanogr 13:36-51

Roe HSJ, Griffiths G (1993) Biological information from an acoustic doppler current profiler. Mar Biol 115:339-346

Roemmich D, Riser S, Davis R, Desaubies Y (2004) Autonomous profiling floats: workhorse for broad-scale ocean observations. Mar Technol Soc J 38:21-29

Editorial responsibility: Hans Heinrich Janssen, Oldendorf/Luhe, Germany
Schaefer KM, Fuller DW (2002) Movements, behavior, and habitat selection of bigeye tuna (Thunnus obesus) in the eastern equatorial Pacific, ascertained through archival tags. Fish Bull 100:765-788

Teo SLH, Boustany A, Blackwell S, Walli A, Weng KC, Block BA (2004) Validation of geolocation estimates based on light level and sea surface temperature from electronic tags. Mar Ecol Prog Ser 283:81-98

$>$ Teo SLH, Boustany AM, Block BA (2007) Oceanographic preferences of Atlantic bluefin tuna, Thunnus thynnus, on their Gulf of Mexico breeding grounds. Mar Biol 152: $1105-1119$

> Weng KC, Castilho PC, Morrissette JM, Landeira-Fernandez AM and others (2005) Satellite tagging and cardiac physiology reveal niche expansion in salmon sharks. Science 310:104-106

Wilson C, Coles VJ (2005) Global climatological relationships between satellite biological and physical observations and upper ocean properties. J Geophys Res C 110:C10001

Yentsch CS, Menzel DW (1963) A method for the determination of phytoplankton chlorophyll and phaeophytin by fluorescence. Deep-Sea Res 10:221-231

Yu XR, Dickey T, Bellingham J, Manov D, Streitlien K (2002) The application of autonomous underwater vehicles for interdisciplinary measurements in Massachusetts and Cape Cod Bays. Cont Shelf Res 22:2225-2245

Submitted: July 24, 2008; Accepted: March 19, 2009 Proofs received from author(s): April 30, 2009 